\title{
The value of abdominal ultrasound in the diagnosis of colon cancer
}

\author{
D. Martínez-Ares, I. Martín-Granizo Barrenechea, J. Souto-Ruzo¹, J. Yáñez López ${ }^{1}$, A. Pallarés Peral and \\ J. L. Vázquez-Iglesias ${ }^{1}$
}

Service of Digestive Diseases. Complejo Hospitalario Universitario Xeral-Cíes. Vigo, Pontevedra. Spain. ${ }^{\text {CComplejo }}$ Hospitalario Universitario Juan Canalejo. A Coruña, Spain

\begin{abstract}
Introduction: colon cancer is one of the main causes of cancer death. Diagnosis requires the examination of the entire large bowel by means of radiological or endoscopic techniques. Many patients suspect of colon cancer are referred for colonoscopy but nevertheless this suspicion is not confirmed after endoscopic examination. The objective of this study is the evaluation of the reliability of abdominal ultrasound in the diagnosis of these tumors.

Material and method: we selected patients suspect of colon cancer referred to the endoscopy unit for a colonoscopy. An abdominal ultrasound was carried out on all patients prior to the endoscopy. Considering the endoscopic examination as a gold standard, the sensibility, specificity, positive predictive value (PPV) and negative predictive value (NPV) of the ultrasonography were evaluated. Likewise, a series of analytical and clinical parameters were evaluated, in an attempt to establish associated factors of a colon cancer. The statistical analysis was carried out by means of the statistical package SPSS 12.0 for Windows.

Results: 145 patients were included in the study $(56.6 \%$ males) with an average 66.72 years of age (22-89). A cancer was diagnosed in 42 cases (28.9\%). In the diagnosis of colon cancer, abdominal ultrasound presents a sensitivity of $79.06 \%$, a specificity of $92.15 \%$, a PPV and a NPV of $80.9 \%$ and of $91.2 \%$, respectively. Excluding from the analysis lesions of the rectal ampulla, which cannot be adequately evaluated by means of ultrasound, the figures for sensitivity, specificity, PPV and NPV increase to 91.8, $92.1,80.9$ and $96.9 \%$ respectively. The univariate analysis showed that an age over 65 years and the presence of microcytosis are associated to a greater risk of colon cancer while after multivariate analysis only the presence of microcytosis resulted to be an independent predictive factor of cancer.

Conclusions: abdominal ultrasound presents high sensitivity, specificity, PPV and NPV in the diagnosis of colon cancer. The combination of an ultrasonography and a rectoscopy permits us to rule out the presence of a colorectal carcinoma. In patients with microcytosis of 65 years and over, if there is strong clinical suspicion, a negative ultrasound may not be sufficient to rule out a colorectal neoplasia.
\end{abstract}

Recibido: 07-04-05.

Aceptado: 06-09-05.

Correspondencia: David Martínez Ares. Servicio de Aparato Digestivo. Complejo Hospitalario Xeral-Cíes. C/ Pizarro, 22. 36204 Vigo (Pontevedra). e-mail: dmartinezares@sepd.es
Key words: Abdominal ultrasound. Colon cancer. Symptomatic patients. Diagnosis. Colonoscopy.

Martínez-Ares D, Martín-Granizo Barrenechea I, Souto-Ruzo J, Yáñez López J, Pallarés Peral A, Vázquez-Iglesias JL. The value of abdominal ultrasound in the diagnosis of colon cancer. Rev Esp Enferm Dig 2005; 97: 877-886.

\section{INTRODUCTION}

Colorectal carcinoma (CRC) is the most frequent gastrointestinal neoplasia, representing approximately $60 \%$ of the total $(1,2)$. It presents a lethality rate lower than that of other tumors, but its high frequency converts it into one of the greatest causes of mortality (1-3). Within the range of digestive tumors it is only surpassed by the mortality of liver cancer and stomach cancer in males and of gastric cancer in women $(3,4)$. The risk of suffering this type of tumor increases with age $(1,2)$, in males $(1,2,4,5)$ and in black people $(1,2)$. In our country these tendencies appear to be maintained, the male/female ratio being 1.64 (1-3). Some studies suggest an association of $\mathrm{CRC}$ to the syndrome of insulin resistance and a sedentary lifestyle $(6,7)$. Smoking $(6,8,9)$, a family history of $\mathrm{CRC}$ and certain nutritious habits, such as the excessive consumption of fatty foods, may also be considered as risk factors (6).

Large geographical variations in relation to the incidence of CRC exist, being 15-25 times higher in the developed countries (10). In Europe, the incidence and the mortality associated to CRC have increased ever so slightly or even can be seen to be reduced thanks to the implementation of screening programs $(6,11,12)$. Nevertheless, in countries such as Greece, Spain and Portugal mortality has continued to grow since adequate screening programs do not yet exist (11). Spain is among the group of countries with the highest mortality rates (3). 
Colon cancer is clinically detected only in very advanced phases, when the prognosis is already not favorable (13). Therefore, early diagnosis is of vital importance. For the moment the gold standard for diagnosis is still the colonoscopy, which also plays a very important preventive role in the removal of precursory lesions (1416). The tumor markers are of little diagnostic value (17), being more useful in the monitoring of tumors and in the diagnosis of family history. For the diagnosis of CRC the examination of the entire large bowel by means of endoscopic or radiological techniques is obligatory (18). Radiological techniques based on obtaining images by means of CT scan or MRI permit a study of the extension of the illness $(18,19)$. The barium enema (20) and especially the double-contrast enema $(21,22)$ are alternatives to the colonoscopy, reaching levels of sensitivity of over $90 \%$. The virtual colonoscopy (23-31) is also a good alternative, although its sensitivity in the detection of smaller lesions has not yet been sufficiently tested. The value of abdominal ultrasound in the diagnosis of CRC has already been established in various studies, however, all involving few patients (32-35). Sonographic findings such as an irregular and hypoecoic thickening of the colon wall and an irregular contour, as well as the loss of stratification in layers of the wall, suggest the diagnosis (33).

Many patients are remitted to the Endoscopy Unit for colonoscopies with a suspected diagnosis which is later not confirmed. The objective of this study is to prospectively evaluate the sensitivity and the specificity of abdominal ultrasound in the diagnosis of colon cancer.

\section{MATERIAL AND METHOD}

\section{Selection of patients}

We selected 150 patients with suspected CRC who were remitted consecutively to the Endoscopy Unit for colonoscopy. These patients were recruited in two different periods and in two different centers: from September 1 to December 31, 2003 in the University Hospital Juan Canalejo, Coruña and from July 1 to October 31, 2004 in the University Hospital Xeral Cíes, Vigo. This was entirely due to a change of workplace of the first author of the study. Patients who had already undergone endoscopic or radiological examination of the colon were excluded, as were, those patients on whom a complete colonoscopy could not be carried out.

\section{Preparation of the patients}

All patients underwent conventional preparation was for colonoscopy consisting of liquid diet the afternoon previous to the procedure, a polyelectrolytic solution with polyethylenglicol (Bohm Solution) and two enemas, one the previous night and another in the morning of the examination.

\section{Method}

Percutaneous abdominal sonography was practiced on all patients before the colonoscopy; both examinations were carried out on the same day in the case of the outpatients, or during the same stay in the case of the hospitalized patients. All the sonographic examinations were carried out by the same observer using the Hitachi EUB525 and Toshiba Nemio 10. Subsequently, endoscopic examinations were carried out by different endoscopists of the Endoscopy Unit of the University Hospital Juan Canalejo in the first period and of the University Hospital Xeral Cíes in the second period, using an Olympus GIF 100 and a Fujinon EC-250WL.

The ultrasonography was carried out according to conventional procedure, carefully examining the entire abdomen. The ultrasound was considered positive when in some of the locations the characteristic image of hypoecoic thickening with loss of mobility and of stratification in layers of the wall was depicted (Fig. 1).

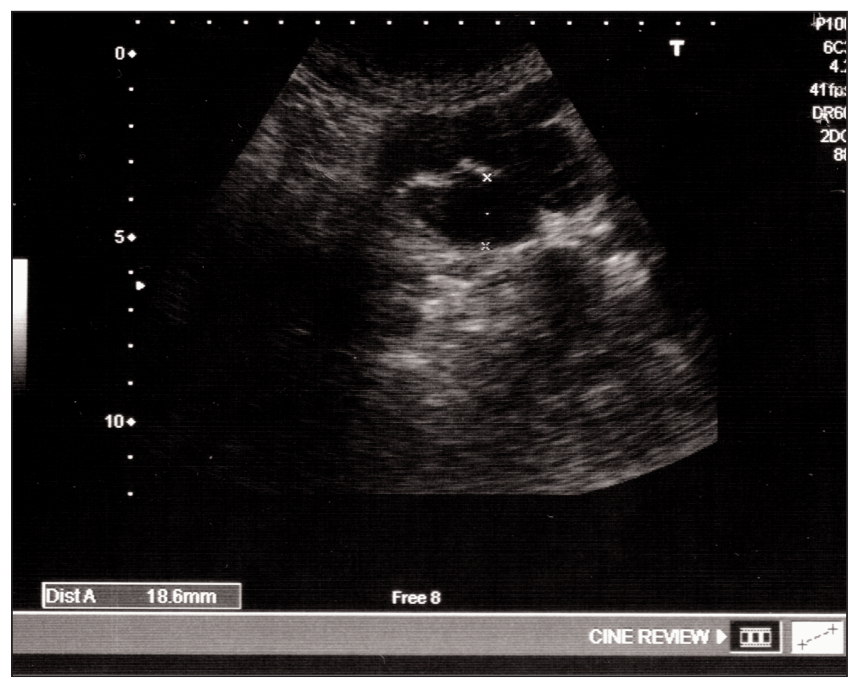

Fig. 1.- We can observe a hypoecoic thickening of the colon wall, whose diameter is of around $15 \mathrm{~mm}$; in addition, the loss of the stratification in layers and the mobility of the intestinal loop are evident.

En la imagen se objetiva un asa de pared muy engrosada, por encima de los $15 \mathrm{~mm}$, con una pérdida total de la estructura en capas de la pared y de la movilidad y compresibilidad del asa.

\section{Variables studied}

In the patients included in the study the demographic characteristics, the clinical characteristics of the patients, the procedure indications, the figures for hemoglobin and of hematocrit, the Mean Corpuscular Volume (MCV), the result of the sonography, the endoscopic findings (type of 
lesion, location, obstructing or not) and the final diagnosis of the patient have been evaluated. Considering the endoscopy as the gold standard in the diagnosis of CRC, the sonographic findings were classified as true positive and negative, false positive and negative.

\section{Statistical analysis}

The statistical study was carried out by means of the statistical package SPSS 12.0 for Windows. Descriptive statistics of the above mentioned variables has been carried out. Subsequently the levels of sensitivity, specificity, positive predictive values (PPV) and negative predictive values (NPV) for the ultrasound in the diagnosis of colorectal carcinoma were calculated manually. Finally, a search for factors associated to a diagnosis of malignancy was carried out among all the variables described in the previous section. The comparison of qualitative variables was carried out based on the Chi squared test. The quantitative variables were transformed into qualitative variables and comparison was also carried out by means of the Chi squared test. The multivariate analysis was carried out by means of a logistic binary regression. The results were considered statistically significant with a value of $\mathrm{p}<0.05$.

\section{RESULTS}

Of the 150 patients selected only 145 (96.6\%) could be finally included. The 5 remaining patients were excluded because the colonoscopy could not be carried out or this could not be completed to caecum.

The average age of the patients included was of 66.72 years (ranging from 22 to 89 years). A $62.1 \%$ of the patients were over 65 . The group was composed for 82 males $(56.6 \%)$ and 63 women $(43.4 \%)$.

The clinical picture of the patients on hospitalization was of digestive hemorrhage in $36.6 \%$ of patients, altered bowel habit in $18.6 \%$, and severe anemic syndrome in $14.5 \%$. The remainder of the patients consulted for other less frequent clinical manifestations (Table I). The patients presented an average hemoglobin of $11.29 \mathrm{~g} / \mathrm{dl}$ (ranging from 3.9 to 16.7 ), a hematocrit of $33,7 \%$ (14.447.6) and a MCV of 84.1 (56-110). Table I shows the distribution of the hemoglobin, MCV and hematocrit counts.

The ultrasonographic examination was normal in 83 cases $(57.2 \%)$, while in 62 cases $(42.8 \%)$ this was pathological. The image compatible with colorectal carcinoma, was established in 42 cases (29\%). In $57.1 \%$, the images were located at the level of the left colon, in $38.1 \%$ at the right colon, in $14.2 \%$ at the left hypochondrium and in $4.6 \%$ at the level of the right hypochondrium. In 34 patients the findings were confirmed by the endoscopy (true positive), while in 8 cases, the endoscopy did not corrob-
Table I. Summary of the demographic variables, analytical parameters and clinical manifestations of the patients included in the study

\begin{tabular}{|c|c|}
\hline Characteristics of the patients & Number of patients (\%) \\
\hline \multicolumn{2}{|l|}{ Age } \\
\hline$<65$ years & 37.9 \\
\hline$>65$ years & 62.1 \\
\hline \multicolumn{2}{|l|}{ Sex } \\
\hline Male & 56.6 \\
\hline Female & 43.4 \\
\hline \multicolumn{2}{|l|}{ Clinical symptoms } \\
\hline Digestive hemorrhage & 36.6 \\
\hline Altered bowel habit & 18.6 \\
\hline Anemic syndrome & 14.5 \\
\hline Abdominal pain & 12.4 \\
\hline Combination of the above & 9.0 \\
\hline Other manifestations & 8.8 \\
\hline \multicolumn{2}{|l|}{ Hematocrit level } \\
\hline$<25$ & 13.8 \\
\hline $25-35$ & 38.2 \\
\hline$>35$ & 47.9 \\
\hline \multicolumn{2}{|l|}{ Mean corpuscular volume } \\
\hline$<78$ & 21.5 \\
\hline$>78$ & 78.5 \\
\hline \multicolumn{2}{|l|}{ Hemoglobin (g/dl) } \\
\hline$<8$ & 13.9 \\
\hline $8-11$ & 28.5 \\
\hline$>11$ & 57.6 \\
\hline
\end{tabular}

orate the sonographic diagnosis (false positive). On the other hand, in 94 patients in which the sonography was negative, the colonoscopy did not locate neoplastic lesions (true negative), while in 9 cases in which the sonography was not conclusive, the colonoscopy revealed the presence of colorrectal neoplasia (false negative). Thus, we conclude that abdominal ultrasound presents a sensitivity of $79.06 \%$, a specificity of $92.15 \%$, a PPV of $80.9 \%$ and a NPV of $91.2 \%$. These results are summarized in table II. In all cases the ultrasonography as much as the colonoscopy detected lesions, the location of the same in the ultrasound was exact, identifying the colonic segment affected.

The colonoscopy did not detect any lesion in 41 patients $(28.3 \%)$, while it did describe pathological findings in 103 cases $(71.7 \%)$, diagnosing a total of $43(29.7 \%)$ malignant neoplasias. In 29 cases $(67.4 \%)$ the lesions significantly obstructed the lumen of the colon, and in 14 cases $(32.6 \%)$ they were lesions of a smaller size. In the 8 cases considered as false negative, 6 lesions $(75 \%)$ were located in the rectum and 6 of them (75\%) were lesions 
Table II. Summary of the results of the sonographic study of patients with suspected CRC

\begin{tabular}{lccc}
\hline & $\begin{array}{c}\text { Patients } \\
\text { with CCR }\end{array}$ & $\begin{array}{c}\text { Patients } \\
\text { without CCR }\end{array}$ & \\
\hline Positive ultrasound & 34 & 8 & 42 \\
\hline Negative ultrasound & 9 & 94 & 103 \\
\hline & 43 & 102 & 145
\end{tabular}

We can deduce from the data that abdominal ultrasound presents a sensitivity of $79.06 \%$, a specificity of $92.15 \%$ a PPV of $80.9 \%$ and an NPV of $91.2 \%$.

of a small size, having no effect on colonic transit. The two obstructing lesions not visualized in the ultrasonography were located in the rectum. On the other hand, in the patients in which a colon cancer was identified in the ultrasound and the colonoscopy did not confirm these findings, in 3 cases (33.3\%), it was a sigmoid colon, extraordinarily spastic in relation to a severe diverticulosis of sigma, in 5 cases $(55.5 \%)$, an inflammatory estenosis or ischemic, and in 1 case the infiltration of the sigmoid colon by a neoplasia of gynecological origin.

If we consider that the rectal ampulla cannot be evaluated by means of percutaneous abdominal ultrasound and we exclude the 6 rectal lesions from the analysis, we are able to affirm that the sensitivity, specificity, PPV and NPV of the ultrasound in the diagnosis of the colorectal carcinoma situated above the rectosigmoid junction are of $91.8,92.1,80.9$ and $96.9 \%$ respectively.

In the statistical analysis carried out to establish factors predictive of colorectal carcinoma, the following variables were included: age, sex, hemoglobin, hematocrit and MCV counts, clinical presence of low digestive hemorrhage, constitutional syndrome, altered bowel habit and results of the sonographic study. The quantitative variables, age, hemoglobin, hematocrit and MCV counts were transformed into categorical variables with 2 possible values (Table III). We observed that $34.4 \%$ of the patients of over 65 years of age presented colon cancer, compared to only $21.8 \%$ of those of less than 65 years of age ( $\mathrm{p}=0.049) ; 51.6 \%$ of the patients who presented macrocytosis $(\mathrm{MCV}<78)$ suffered colon cancer while only $23.9 \%$ of those with normal MCV presented a positive colonoscopy $(\mathrm{p}=0,004)$. Finally, while $81 \%$ of patients with a positive sonography presented colon cancer, only $8.7 \%$ of the patients with negative sonography presented it $(p<0.0001)$. In the multivariate analysis, carried out by means of a logistic binary regression, only the positive ultrasonography and the presence of microcytosis in blood tests were shown as independent factors predictive of a colonic neoplasia, with an odds ratio of 9.26 (IC $95 \%$ 4.8 to 17.5 ) and of 2.16 (IC 95\% 1.34 to 3.46 ) respectively.

\section{DISCUSSION}

Although the studies carried out to date are scarce involving few patients, some data on the high sensitivity of abdominal ultrasound in the diagnosis of the colorectal
Table III. Variables included in the univariate analysis

\begin{tabular}{lcc}
\hline Variables & Colorectal carcinoma (\%) & p \\
\hline Age (years) & & \\
$\quad<65$ & 21.8 & \\
$\quad>65$ & 34.4 & 0.049 \\
Sex & & \\
$\quad$ Male & 25.6 & \\
$\quad$ Female & 34.9 & 0.272 \\
Low digestive hemorrhage & & \\
$\quad$ No & 33 & \\
$\quad$ Yes & 24.1 & 0.492 \\
Hematocrit level & & \\
$\quad>25 \%$ & 29.3 & \\
$\quad<25 \%$ & 33.3 & \\
Constitutional syndrome & & \\
$\quad$ No & 30.486 \\
$\quad$ Yes & 28 & \\
Altered bowel habit & & \\
$\quad$ No & 31 & \\
$\quad$ Yes & 24.1 & 0.981 \\
Mean corpuscular volume & & \\
$\quad>78$ & 23.9 & 0.650 \\
$\quad<78$ & 51.6 & \\
Hemoglobin & & \\
$\quad>8$ g/dl & & \\
$\quad<8$ g/dl & 35 & \\
Positive ultrasound & & \\
$\quad$ No & & \\
$\quad$ Yes & & \\
\hline
\end{tabular}

We can observe that patients of over 65 years of age with microcytosis and with a positive ultrasound are present in significantly greater frequency.

carcinoma already exists. In their study Rutgeerts et al. (32) observed a high sensitivity of $95 \%$, although accompanied by low specificity. Richardson et al. (33) obtained similar results, with a sensitivity of $96 \%$ and a specificity of $67 \%$. On the contrary, Shirahama et al. (34) obtained a specificity of $90 \%$. In our study of 145 patients where 43 tumors were diagnosed, the levels of sensitivity are lower than those published previously (79\%) and the figures for specificity are congruent with the study of Shirahama $(92 \%)$. Nevertheless, if we exclude the tumors located in the rectal ampulla, which cannot be evaluated adequately by means of abdominal ultrasound, we obtain a sensitivity practically equal to that of the other authors. As it is logical, the small-sized polypoid lesions that do not affect the intestinal lumen are not detected by ultrasonography, while lesions of greater size are easily visualized. Thus, Lim et al. (35) studied patients with intestinal obstruction, of neoplastic and of other origins, and with abdominal sonography gave the precise location and cause in most cases.

Only two studies compare the sonography with other techniques. Loftus et al. (36) in a study that includes only 7 patients with colon cancer, the conclusions of which are of little weight, considered the abdominal ultrasound 
clearly superior to the CT scan. The ultrasonography presents a sensitivity and specificity of $100 \%$, figures significantly higher than those obtained in other studies. Candia et al. (37) compared the hydrocolonic ultrasound with the double-contrast enema. The hydrocolonic ultrasound presents a lower sensitivity in the diagnosis of polyps of small size $(80 v s .92 \%)$ but greater specificity (100 vs. 92.8\%); nevertheless, in the diagnosis of CRC it presents a higher sensitivity (96.8 vs. 90.6\%) and the same specificity $(100 \%)$. Both sensitivity and specificity are higher than those obtained for the conventional ultrasound.

In fact the hydrocolonic ultrasound, carried out after the retrograde instillation of a water enema, permits the examination of the entire large bowel from the rectosigmoid in $97 \%$ of patients (38). It also permits the visualization of the five layers of the colon wall showing the complete characteristics of the tumor (38). The sensitivity in the detection of CRC in the different studies oscillates between 83 and $97 \%$ and the specificity is in and around $98 \%$ (38-43). Additionally, the precision in the T staging oscillates between 70 and $98 \%(40,43)$. In our study, all patients have been studied using the conventional technique and, if we exclude the cases of rectal cancer as they have done in the hydrocolonic sonography studies, the figures of sensitivity and specificity are quite similar while the technique requires less time and is more comfortable for the patient. On the other hand, the conventional technique does not permit an adequate recognition of the $\mathrm{T}$ staging. However, the hydrocolonic ultrasound is only precise in the appraisal of the $\mathrm{T}$ staging. Other techniques are needed to determine the presence of adenopathies or distant metastases, and thus it is not clear that the value of the hydrocolonic sonography is greatly superior to that of the conventional technique.

Therefore, abdominal sonography represents a specific and very sensitive technique in the detection of colon cancer. It is a simple technique that does not require excessive time for its completion, very well tolerated by the patients and practically risk-free. It should be respected as an alternative to the conventional radiological and endoscopic tests where these techniques are not possible and even in those in which the diagnosis is not clear. The paradigm could be the patients with microcytic anemia and constitutional syndrome, accompanied by non-specific digestive symptoms; in these patients on the list of differential diagnoses the presence of a colon cancer is included, but this list can be quite long. The abdominal sonography as a first diagnostic test may justify carrying out an endoscopic examination and also the choice of the first test to be undergone, since tumors of the gastroduodenal area can also be visualized by the ultrasound. Further well-designed study is needed to confirm the viability of this hypothesis. Nevertheless, highly suspect CRC patients such as those patients over 65 years, with suggestive symptoms and microcytic anemia (the analytic and clinical data which in our patients best predicts the presence of a cancer) a negative ultrasonography should not exclude endoscopic examination since rectal tumors cannot be detected by means of the ultrasound. But it is possible that in these patients a rectoscopy, less invasive and less costly than a complete colonoscopy, may be sufficient.

Shortly, the abdominal sonography presents high sensitivity and specificity in the diagnosis of tumors located above the rectosigmoid junction. However, the sensitivity in the detection of polipoid lesions of small size is very low, and thus, this technique cannot be proposed for the screening of CRC above all if we keep in mind that the detection and removal of the polyps of the colon has reduced the incidence and mortality rates of colon cancer.

\section{REFERENCES}

1. Parkin, DM, Pisani P, Ferlay J. Global Cancer Statistics. CA Cancer J Clin 1999; 49: 33-64

2. Greenlee RT, Murray T, Bolden S, Wingo PA. Cancer Statistics, 2000. CA Cancer J Clin 2000; 50: 7-33.

3. Shibuya K, Mathers CD, Boschi-Pinto C, López AD, Murray CJL. Global and regional estimates of cancer mortality and incidence by site: II. Results for the global burden of disease 2000 BMC Cancer 2002, 2 (www.biomedcentral.com/1471-2407/2/37)

4. Pisani P, Parkin DM, Bray F, Ferlay J. Estimates of the worldwide mortality from 25 cancers in 1990. Int J Cancer 1999; 83: 18-29.

5. Bonithon-Kopp C, Benhamiche AM. Are there several colorectal cancers? Epidemiological data. Eur J Cancer Prev 1999; 8 (Supl. 1): S3-12.

6. Becker N. Epidemiology of colorectal cancer. Radiologe 2003; 43: 98-104.

7. Colangelo LA, Gapstur SM, Gann PH, Dyer AR, Liu K. Colorectal cancer mortality and factors related to the insulin resistance syndrome. Cancer Epidemiology, Biomarkers \& Prevention 2002; 11 : 385-91.

8. Sharpe CR, Siemiatycki JA, Rachet BP. The effects of smoking on the risk of colorectal cancer. Dis Colon Rectum 2002; 45: 1041-50.

9. Anderson JC, Attam R, Alpern Z, Messina CR, Hubbard P, Grimson $\mathrm{R}$, et al. Prevalence of colorectal neoplasia in smokers. Am J Gastroenterol 2003; 98: 2777-83.

10. Bonithon-Kopp C, Benhamiche AM. Are there several colorectal cancers? Epidemiological data. Eur J Cancer Prev 1999; 8 (Supl. 1): S3-12.

11. Quinn M. J. Cancer Trends in the United States. A View From Europe. J Natl Cancer Inst 2003; 95: 1258-61.

12. Ries LAG, Wingo PA, Daniel S, Howe HL, Weir HK, Rosenberg HM, et al.The Annual Report to the Nation on the Status of Cancer, 1973-1997, with a Special Section on Colorectal Cancer. Cancer 2000; 88: 2398-424.

13. Carter PS, Myint AS, Hershman MJ. Improving outcomes in colonic cancer. Hosp Med 2000; 61: 703-5.

14. Nelson D. Colonoscopy and polypectomy. Hematol Oncol Clin North Am 2002; 16: 867-74.

15. Kronborg O. Colon polyps and cancer. Endoscopy 2002; 34: 69-72.

16. Rex DK, Bond JH, Feld AD. Medical-legal risks of incident cancers after clearing colonoscopy. Am J Gastroenterol 2001; 96: 952-7.

17. Crawford NP, Colliver DW, Galandiuk S. Tumor markers and colorectal cancer: utility in management. J Surg Oncol 2003; 84: 239-48.

18. Dobos N, Rubesin SE. Radiologic imaging modalities in the diagnosis and management of colorectal cancer. Hematol Oncol Clin North Am 2002; 16: 875-95.

19. Elmas N, Killi RM, Sever A. Colorectal carcinoma: radiological diagnosis and staging. Eur J Radiol 2002; 42: 206-23.

20. Bolin S, Franzen L, Nilsson E, Sjodahl R. Carcinoma of the colon and rectum. Tumors missed by radiologic examination in 61 patients.Cancer 1988; 61: 1999-2008.

21. Levine MS, Rubesin SE, Laufer I, Herlinger H. Diagnosis of colorectal neoplasms at double-contrast barium enema examination. Radiology 2000; 216: 11-8. 
22. Connolly DJ, Traill ZC, Reid HS, Copley SJ, Nolan DJ. The double contrast barium enema: a retrospective single centre audit of the detection of colorectal carcinomas. Clin Radiol 2002; 57: 29-32.

23. Fletcher JG, Luboldt W. CT colonography and MR colonography: current status, research directions and comparison. Eur Radiol 2000; 10: 786-801.

24. Johnson CD, Dachman AH. CT colonography: the next colon screening examination? Radiology 2000; 216: 331-41.

25. Summers RM. Challenges for computer-aided diagnosis for CT colonography. Abdom Imaging 2002; 27: 268-74.

26. Gluecker TM, Fletcher JG. CT colonography (virtual colonoscopy) for the detection of colorectal polyps and neoplasms. current status and future developments Eur J Cancer 2002; 38: 2070-8.

27. Macari M, Bini EJ, Jacobs SL, Lange N, Lui YW. Filling defects at CT colonography: pseudo- and diminutive lesions (the good), polyps (the bad), flat lesions, masses, and carcinomas (the ugly). Radiographics 2003; 23: 1073-91.

28. Dixon GD. Computed tomography for screening purposes: a review of the literature-2003. Mo Med 2003; 100: 140-4.

29. Dachman AH. Virtual colonoscopy. Potential clinical applications of a new technique. Gastroenterol Clin North Am 2002; 31: 747-57.

30. Dachman AH. Diagnostic performance of virtual colonoscopy. Abdom Imaging 2002; 27: 260-7.

31. Kuwayama H, Iimuro M, Kitazumi Y, Luk G. Virtual endoscopy: current perspectives. J Gastroenterol 2002; 37 (Supl. 13): 100-5.

32. Rutgeerts LJ, Verbanck JJ, Crape AW, Buyse BM, Ghillebert GL. Detection of colorectal cancer by routine ultrasound. J Belge Radiol 1991; 74: 11-3.

33. Richardson NG, Heriot AG, Kumar D, Joseph AE. Abdominal ultrasonography in the diagnosis of colonic cancer. Br J Surg 1998; 85 (4): 530-3.

34. Shirahama M, Koga T, Ishibashi H, Uchida S, Ohta Y. Sonographic features of colon carcinoma seen with high-frequency transabdominal ultrasound. J Clin Ultrasound 1994; 22 (6): 359-65.

35. Lim JH, Ko YT, Lee DH, Lee HW, Lim JW. Determining the site and causes of colonic obstruction with sonography. AJR Am J Roentgenol 1994; 163(5): 1113-7.

36. Loftus WK, Metreweli C, Sung JJY, Yang WT, Leung VKS, Set PAK. Ultrasound, CT and colonoscopy of colonic cáncer. B J Radiol 1999; 72: 144-8.

37. Candia C, Ciacci V, Di Segni R, Santini E. Hydrocolonic sonography in the study of colonic diseases. Comparison with double-contrast enema. Radiol Med (Torino) 1995; 89 (3): 258-63.

38. Limberg B. Diagnosis of colonic tumors and chronic inflammatory colonic diseases by hydrocolonic sonography. Radiologe 1993; 33 (7): 407-11

39. Walter DF, Govil S, William RR, Bhargava N, Chandy G. Colonic sonography: preliminary observations. Clin Radiol 1993; 47 (3): 200-4.

40. Hernández-Socorro CR, Guerra C, Hernández-Romero J, Rey A Lopez-Facal P, Álvarez-Santullano V. Colorectal carcinomas: diagnosis and preoperative staging by hydrocolonic sonography. Surgery 1995; 117 (6): 609-15.

41. Segura JM, Molina E, Herrera A, Berges MA, Erdozain JC, Arjonilla A, et al. Hidrocolonic ultrasonography in the detection of tumoral processes in the inferior gastrointestinal tract. Rev Esp Enferm Dig 1998; 90 (11): 779-87.

42. Limberg B. Diagnosis and staging of colonic tumors by conventional abdominal sonography as compared with hydrocolonic sonography. N Engl J Med 1992; 327 (2): 65-9.

43. Dux M, Roeren T, Kuntz C, Richter GM, Kauffmann GW. TNM staging of gastrointestinal tumors by hydrosonography: results of a histopathologically controlled study in 60 patients. Abdom Imaging 1997; 22 (1): 24-34. 